\title{
Quality of informed consent in clinical trials
}

\author{
Anna Zagaja, ${ }^{1, A-F}$ \\ ${ }^{1}$ Department of Ethics and Medical Law, Medical University of Lublin, Poland \\ A - Research concept and design, B - Collection and/or assembly of data, C - Data analysis and interpretation, \\ $D$ - Writing the article, E-Critical revision of the article, F- Final approval of article
}

Zagaja A. Quality of informed consent in clinical trials. J Pre-Clin Clin Res. 2020; 14(1): 22-24. doi: 10.26444/jpccr/119621

\begin{abstract}
Introduction and objectives. Obtaining consent prior to any medical intervention is currently a necessity, the omission of which may lead to litigation. Years of analyses have resulted in strict policies as to what should the patient be informed about and who should provide such information. It would seem reasonable to assume that the concept of informed consent does not lead to any more quarries, however within the past few years a new concept pertaining to the quality of informed consent emerged. The aim of the article is to bring this concept closer.

Description of state of knowledge. Quality of informed consent pertains to the information a patient understood during the consent process and the conditions under, which consent was obtained. Recent publications underline a discrepancy between what the patient knows and what the patient should know under the set requirements of informed consent. Research indicates that many clinical trial participants do not understand the provided information and are unable to enumerate basic items such as risk or benefits of the trial. What is more, the forms they obtain are too elaborate and do not facilitate the decision making process. All this undermines the essence of informed consent and decreases its quality.

Conclusions. Despite years of working on the process of obtaining informed consent and elaborate forms that should facilitate decision making for patients, the information the patients have prior to entering the clinical trial are frequently insufficient to term the consent they make informed.
\end{abstract}

\section{Key words}

informed consent, quality of informed consent, clinical trials

\section{THE CONCEPT OF INFORMED CONSENT}

Although 'Informed consent' is a term coined in the late 1950s, it would be misleading to believe that the considerations concerning consent are attributed solely to that decade. Already in Ancient times, doctors underlined the necessity to treat patients with their approval and history has witnessed numerous cases of such considerations. Reflections on a patient's autonomy initiated the acceleration of the discussion on consent as an indicator of the afore-mentioned concept. The past 120 years of scandals associated with lack of consent resulted in legal regulations that shaped the currently existing concept of consent. It is interesting that the first legal regulations in the United States associated with consent were the result of individual lawsuits for wrongdoing, whereas in Europe, it originated from inappropriately conducted medical research. One of the first such cases concerned research conducted at the end of the XIX century by Professor Albert Neisser, in which he tested an anti-syphilis vaccine on his venereology clinic patients without their prior consent[1]. Because several then fell ill with the disease, the question of patient autonomy began to be a problem that reached the Prussian government and resulted in restrictions regarding future medical research [2]. For the next century, the restrictions governing research were broadened by new regulations concerning the issue of informed consent, most of them as an outcome of various scandals, i.e. enactment of the Food, Drug, and Cosmetic Act after the 1937 sulfanilamide elixir scandal, introduction of the Belmont Report after the Tuskegee Syphilis Study, and more recently, the Nuremberg Code after World War II, [3].

Addresss for correspondence: Anna Zagaja, Medical University of Lublin, Poland E-mail: anna.zagaja@umlub.pl

Received: 21.03.2020; accepted: 25.03.2020; first published: 31.03 .2020
It would seem reasonable to believe that the concept of consent has been analyzed from the ethical/legal perspective in such detail that it should no longer give rise to any further controversy $[4,5,6,7]$; numerous publications indicate that the requirements for obtaining consent are set, and in case of medical research, strict. However, the problem of the quality of informed consent, which questions the whole concept of 'informed consent', begins to emerge. Quality of informed consent can be defined by assessing the possessed knowledge, i.e. what the person understood from the information provided, whether the benefits and risks were well balanced, and analyse the conditions under which the consent was delivered (peace, quiet), as well as the attitude of the person giving consent (willing to take time to answer questions, asking for feedback, etc.). The objective of the article is to acquaint the readers with the concept of the quality of informed consent in clinical trials.

\section{QUALITY OF INFORMED CONSENT AS A CHALLENGE OF THE 21ST CENTRY}

The ethical principle of autonomy requires that in the process of giving informed consent, the patient must be thoroughly informed about the proposed procedure, its benefits, risks and alternatives, or the possibility to withdraw at any time. After being provided with the necessary information, the patient should then make an autonomous, voluntary decision as to whether or not participate. Despite years of legal and ethical considerations, the problem of requirements for informed consent and the impossibility of fulfilling them has been a subject in numerous publications. Already in the 1970s, researchers began to question the concept of informed consent and to underline its limits $[8,9]$. Fifty years later, 
informed consent still poses a dilemma, this time in terms of its quality. Although the concept of quality of informed consent is visible in all fields of medicine, the current article focuses solely on clinical trials.

In short, consent should be proceeded by providing information, analysing the obtained information by the patient, and in the event of agreement, signing the consent form. After these steps, the clinical trial may be initiated. The question of quality is a question of the patient's knowledge, and the overall conditions under which consent was granted. The central part of the informed consent process providing broad knowledge about the proposed trial, is the informed consent forms (ICF). The consent forms should include all information enumerated as necessary [10] and be signed by the person to undergo the clinical trials or his/her legal representative or guardian. However, it has been noted that informed consent forms are too long, too elaborate, and their understanding requires a high reading level. Research conducted by Meza-Lopez et al. on 39 informed consent forms (ICF's) from 13 pharmaceutical companies for industrysponsored clinical trials in rheumatology, conducted over a 17 -year period, revealed that majority of respondents found the forms to be either 'somewhat difficult to read' or 'average'. In the current study, a significant increase was observed in the length of consent forms between the forms written between 1999 - 2005 (13 \pm 5 pages) and after 2005 (22 \pm 8 pages; $\mathrm{p}<0.01$ )[11]. Studies conducted by Bloswick on Polish forms seem to confirm the trend of an increasing number of pages in ICFs [12]. To improve this situation, the Czech Republic, Spain, The Netherlands, United States and Israel (among others) implemented restrictions on the maximum number of pages in the ICFs; however, to circumvent these restrictions, some companies reduced the font size, expanded the margins, and added pages at the end of the document [13, 14]. A study by G. Wen on Chinese and international ICFs revealed a difference between national and international forms in terms of readability and content integrity, with a benefit towards the latter. The Chinese forms were evaluated as difficult to read, with poor descriptions of alternatives, a low degree of information on future data/sample processing, inclusion criteria or unpredictable risks [15] Interestingly, the growing number of pages does not result in the patient's better understanding. Out of 90 patients taking part in the perception questionnaire conducted by A. S. Meza-Lopez et al., 84 stated that they understood the ICFs; however, a closer analysis revealed that $2 \%-57 \%$ misunderstood the basic concepts of the research, including the name of the study drug, randomization and placebo [11].

In 2001, Joffe et al. developed a new tool to assess the quality of informed consent in cancer clinical trials. The Quality of Informed Consent (QuIC) is a valid and reliable questionnaire that evaluates the quality of understanding obtained during the informed consent process [16]. Despite such initiatives, a lack of understanding of clinical trials is still observed in various parts of the world. The World Health Organization (WHO) conducted an analysis of 103 studies which discovered that the understanding of different components of informed consent, varied. The overall results indicated that majority of research participants understood that they could withdraw from research at any moment (75.8\%), and majority understood the nature of the study and its voluntary character. $33 \%$ of the research participants were not aware of potential risks and side-effects, and 33.8\% were unaware of the right to confidentiality. The lowest scores were obtained regarding risk factors; on average, $54.9 \%$ of participants were able to enumerate at least one risk factor, whereas understanding the meaning of placebo and randomization was yet another problem (Fig. 1). It was also found that the knowledge part of informed consent had not improved over the past 30 years [17].

Research conducted by K. Sei-Hill revealed that it is subjective knowledge and perceived risks that are significant in determining the willingness to undergo clinical trials. The more the knowledge and the less the perceived risks, the more lenient a person was towards participation [18]. A discrepancy between perception of clinical trials and the willingness to participate was also observed in research by Yun Jung Choi et al. and was associated with previous experience with clinical research, or being otherwise aware of such a possibility. The authors argued that perceiving a trial as meaningful may, in fact, be associated with previous knowledge, and not information obtained just before the trial. The authors of the above-cited study also placed great importance on the Internet and media as carriers of such information as the majority of research participants searched for information on the Internet [19]. In terms of informed consent, recently a trend has been observed of posting ICFs on-line as a method of acquainting the future research participants with the trial, and simultaneously facilitating the decision-making process. This is also a way to maintain research transparency [20]. In the light of the previous information, in fact, the Internet can be a great source of knowledge on the condition that the research participants are able to separate perceived and actual knowledge.

\section{CONCLUSIONS}

Clinical trials are an essential part of increasing the quality of life of individual patients, and improving the current state of medical knowledge. The ethical concept of patient autonomy requires that prior to any interference into the human body, the patient should be informed about the basic concepts governing the trial so that the choice made will be an informed one. Although the theory is elaborate and should translate into practice, research results reveal tha, $t$ in fact, it does not. Participants in clinical trials are not always aware of the basic concepts of the trials; they are unaware of the risks and consequences, the meaning of placebo and randomization, they sometimes do not understand the objectives of the proposed trial and have various misconceptions. Additionally, they do not understand the Informed Consent Forms, which paradoxically were created to facilitate the decision-making process. The consent forms for clinical trials are sometimes considered as law focused, rather than patient focused, and in the case of long, elaborate informed consent forms this may in fact be a reasonable assumption. All the above questions the concept of the quality of informed consent, and through that the whole concept of patient autonomy.

\section{Acknowledgements}

The author expresses thanks Jakub Pawlikowski for his expert review. 


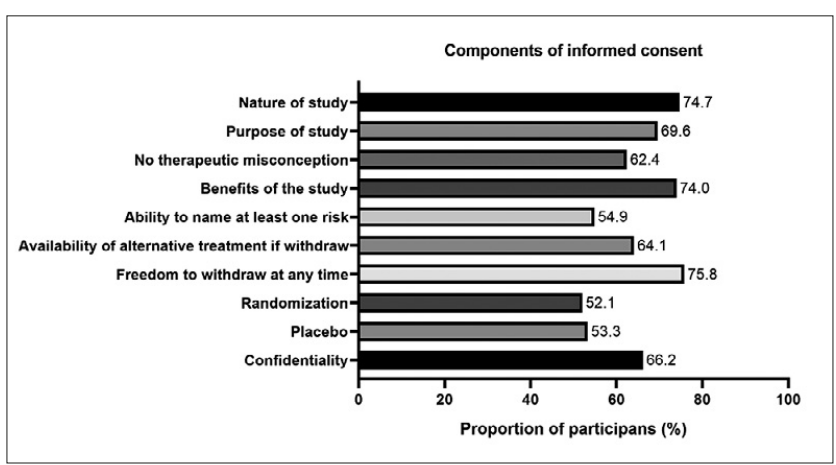

Figure 1. Components of informed consent. According to Tam NT, et al. [17]

\section{REFERENCES}

1. Oriel JD. Eminent venereologists. 1. Albert Neisser. Genitourin Med. 1989; 65(4): 229-234. doi: 10.1136/sti.65.4.229

2.Vollmann J, Winau R. Informed consent in human experimentation before the Nurenberg code. BMJ 1996; 313(7070): 1445-1449. doi: 10.1136/bmj.313.7070.1445

3. Czarkowski M, Różyńska J. Świadoma zgoda na udział w eksperymencie medycznym. Poradnik dla badacza. Warszawa: Naczelna Izba Lekarska, Ośrodek Bioetyki Naczelnej Rady Lekarskiej, 2008.

4. Kodeks Etyki Lekarskiej Dostepny. http://www.nil.org.pl/_data/assets/ pdf_file/ 0003/4764/Kodeks-Etyki-Lekarskiej.pdf (accessed 10.03.2019).

5. Konstytucja RP Rzeczypospolitej Polskiej z dnia 2 kwietnia 1997 r. (DzU $1997 \mathrm{nr} 78$ poz. 483).

6. Ustawa $\mathrm{z}$ dnia 5 grudnia 1996 r. o zawodach lekarza i lekarza dentysty (tj. DzU z 2019 r. poz. 537, 577, 730, 1590).

7. Ustawa z dnia 6 listopada 2008 r. o prawach pacjenta i Rzeczniku Praw Pacjenta (DzU 2009 Nr 52, poz. 417).

8. Alfidi RJ. Controversy, Alternatives, and Decisions in Complying with the Legal Doctrine of Informed Consent. Radiology 1975; 114(1): 231-234. doi: 10.1148/114.1. 231

9. Katz J. Informed consent--a fairy tale? Law's vision. Univ Pittsbg Law Rev. 1977; 39(2): 137-174.
10. The United States Federal Food, Drug, and Cosmetic https://www.fda. gov/patients/clinical-trials-what-patients-need-know/informed-conse nta-clinical-trials (accessed 10.03.2019)

11. de la Mora-Molina H, Barajas-Ochoa A, Sandoval-Garcia L, NavarreteLorenzon M, Castańeda-Barragan EA, Castillo-Ortiz JD, AcevesAvila FJ, Yańez J, Bustamante-Montes LP, Ramos-Remus C. Trends of informed consent forms for industry-sponsored clinical trials in rheumatology over a 17-year period: readability, and assessment of patients' health literacyand perception Semin Arthritis Rheum. 2018; 48(3): 547-552. doi: 10.1016/j.semarthrit.2018.03.008

12. Bloswick A, Skowron A. Length and format of informed consent forms in clinical trials in different patient populations (pediatric, adult, elderly) based on samples from Poland. Ethics \& Medicine 2017; 33: 97-105.

13. Cohen O, Mishel M, Lugassy G. Informed Consent Form in Israel Clinical Trials, UNESCO Chair in Bioethics 12th World Conference, Limassol, Cyprus, March 2017.

14. Bloswick A, Skowron A. Informed Consent Documentation in Pharmaceutical Industry - Sponsored Clinical Trials. Ethics \& Medicine 2015; 31: 51-58.

15. Wen G, Liu X, Huang L, Shu J, Xu N, Chen R, Huang Z, Yang G, Wang X, Xiang Y, Lu Y, Yuan H. Readability and Content Assessment of Informed Consent Forms for Phase II-IV Clinical Trials in China. PLoS One. 2016; 11(10): e0164251. doi:10.1371/journal.pone.0164251

16. Joffe S, Cook EF, Cleary PD, Clark JW, Weeks JC. Quality of informed consent: a new measure of understanding among research subjects. J Natl Cancer Inst. 2001; 93(2): 139-47. https: //doi.org/10.1093/jnci/93.2.139

17. Tam NT, Huy NT, Thoale TB, Long NP, Trang NT, Hirayama K, Karbwang J. Participants' understanding of informed consentin clinical trials over three decades: systematic review and meta-analysis. Bull World Health Organ 2015; 93(3): 186-98H. doi: 10.2471/BLT.14.141390

18. Kim SH, Tanner A, Friedman DB, Foster C, Bergeron C. Barriers to Clinical Trial Participation: Comparing Perceptions and Knowledge of African American and White South Carolinians. J Health Commun. 2015; 20(7): 816-26. doi: 10.1080/10810730. 2015.1018599

19. Choi YJ, Beck SH, Kang WY, Yoo S, Kim SY, Lee JS, Burt T, Kim TW. Knowledge and perception about clinical research shapes behavior: face to face survey in Korean general public. J Korean Med Sci. 2016; 31(5): 674-681. doi: 10.3346/jkms. 2016.31.5.674

20. Final Rule: Federal Policy for the Protection of Human Subjects. Federal Register. 2017; 82(12): 7149-7274. https://www.gpo.gov/fdsys/pkg/FR2017-01-19/pdf/2017-01058.pdf. (herein after “Revised Common Rule”). 